
July 1942

\title{
MICROSCOPIC STRUCTURE OF FLAX AND RELATED BAST FIBERS
}

\author{
By Charles W. Hock ${ }^{1}$
}

\section{ABSTRACT}

The microscopic structure of flax and of related bast fibers was investigated. The stem of the flax plant consists of two main parts, a central woody core, and a surrounding cortex which contains the bast fibers. The cambium layer lies between these regions. Retting involves, essentially, a softening of the tissues to permit separation of the fibers from the other parts of the stem. The cambium layer is attacked first during this treatment, followed later by attack on other thin-walled cells in the cortex.

Flax and related bast fibers, such as hemp, jute, and ramie, have a similar origin and structure. They are obtained from the stem in the form of long filaments, each of which is made up of cells. In this respect they differ from cotton fibers, which are single plant cells.

A flax cell has a primary and a secondary wall. The former constitutes the surface of each cell and consists largely of wax and other material, much of which has generally been assumed to be of a pectic nature. The secondary wall, which comprises the bulk of the fiber, is made up of innumerable cellulose fibrils, the outermost layer of which winds in one direction, whereas the majority of the fibrils beneath this layer wind in the opposite direction. These fibrils are grouped so as to give the wall a lamellar pattern. There is a greater number of these layers in the walls of the cells at the base of the stem than in the cells from the growing tip. A corresponding increase in thickness of the wall, from the tip of the stem where the cells originate to the base where they mature, also prevails. All the bast fibers have essentially similar structures. Flax and ramie, however, differ from hemp and jute in the directions of fibrillate orientation, and this accounts for some of the differences in the physical properties of the two groups.

\section{CONTENTS}

I. Introduction $\ldots \ldots \ldots 1$

II. Materials

III. Experimental procedure and results

1. Flax fibers in cuprammonium reagent

2. Lamellas.

3. Fibrillate structure

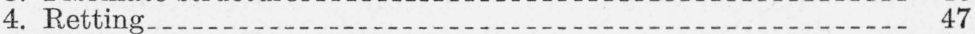

IV. Comparison of flax with other bast fibers $\ldots \ldots$

\section{INTRODUCTION}

Flax fibers are obtained from the stem of the flax plant. The stem consists essentially of a central woody core, and a surrounding cortex which contains the flax or bast fibers. The thin cambium layer lies between these regions. The fibers are obtained from the plant in the form of long filaments, each of which is made up of cells. Other bast

\footnotetext{
1 Research Associate at the National Bureau of Standards, representing the Textile Foundation.
} 
fibers, such as hemp, jute, and ramie, have a similar origin and structure. Although the bast fibers have many structural details like those in cotton, they differ from it in one important respect, namely, a cotton fiber is a single plant cell, whereas a bast fiber is made up of a group of cells.

A flax cell has a primary and a secondary wall. In accordance with the terminology used by Bailey [1], ${ }^{2}$ the primary wall is considered to be the outer sheath of the fiber, or that portion of the wall which is laid down during the period of active elongation of the cell. The secondary wall is that part which is subsequently deposited on the inside of the primary wall, and which is largely responsible for the useful properties of the fiber. The adjacent cells are held together by a layer of intercellular substance.

At the tip of a growing flax stem all the cells are essentially alike. They are relatively small and uniform, and have a tenuous primary wall. A short distance back from the growing point the cells that are to develop into fibers increase in dimensions, and deposition of the secondary wall is initiated.

Considerable information concerning the structure of flax is available from the work of Tammes [2], Nodder [3, 4], Searle [5], Herzog [6], Anderson [7], Osborne [8], and others. In the present investigation many of these earlier observations have been confirmed and extended by applying to the flax fiber those methods and techniques which have recently been used to advantage in studying the structure of the cotton fiber.

\section{MATERIALS}

Two varieties of Linum usitatissimum, Martin and Jlord, were used for most of the experiments. The samples of the former variety consisted of dried flax plants, flax straw, retted straw, scutched line fiber, and machine-hackled line fiber. This material was grown in Oregon and supplied through the courtesy of the Bureau of Plant Industry, U. S. Department of Agriculture. ${ }^{3}$ Plants of the second variety were grown from seed, in pots in the laboratory. For comparison, about 15 other samples each of flax, hemp, jute, and ramie were used. This material included fibers which had received various treatments during manufacture.

A few experiments were carried out with commercially retted fibers, but for the most part the investigation was limited to fibers that had received as few treatments as possible. This was accomplished by careful dissection of single fibers from flax straw, such fibers being termed "raw fibers." The natural waxes were removed from some of the raw fibers by extraction with alcohol and ether for 24 hours each. These fibers are termed "dewaxed fibers." A portion of the dewaxed material was further purified by boiling with 5-percent sodium hydroxide until the fibers were practically free of intercellular substance, and of much of the primary wall. These fibers, after removal of the material which has generally been assumed to be pectic in nature [1, 9], are designated "depectinized fibers."

The cuprammonium hydroxide solution, used for dissolving and for swelling the cellulose, was prepared according to the recommendation of Mease [10]. Trimethylbenzylammonium hydroxide was used in

2 Figures in brackets indicate literature references at the end of this paper.

3 Acknowledgment is made to B. B. Robinson and E. G. Nelson for supplying this material. 
some of the experiments. The stock solution, which was $2.5 \mathrm{~N}$, was diluted with water just before using to about $2.2 \mathrm{~N}$. For staining cellulose, iodine and sulfuric acid [11], zinc chloride-iodine [11], and an alkaline solution of Congo red ( 0.5 percent of dye in a 0.5 -percent solution of sodium hydroxide) were used. Aqueous solutions of ruthenium red were suitable for staining pectic compounds [12]. Although ruthenium red is not a specific stain for pectic substance, native pectic compounds are invariably colored by it [13].

\section{EXPERIMENTAL PROCEDURE AND RESULTS}

\section{FLAX FIBERS IN CUPRAMMONIUM REAGENT}

In an earlier investigation on the behavior of cotton in cuprammonium hydroxide solution it was shown that the cellulose of the fibers dissolves, leaving residues which vary in amount and in structure, depending upon the extent of purification of the fibers [14]. In the present study similar results were obtained with flax. When raw and dewaxed fibers were placed on microscope slides and then treated with cuprammonium reagent the fibers swelled and twisted, and separation of the individual cells occurred. The fibers were attacked first at the characteristic surface markings, which Osborne [8] has shown to be fissures in the wall. That these markings are actual fissures explains why they became more prominent when the fibers were given microchemical color tests for cellulose (fig. 1), and also why the cuprammonium reagent attacked these regions first. The latter phenomenon was especially noticeable when the observations were made with the crossed nicols of a polarizing microscope. The fibers, originally bright against a dark field, became progressively dimmer as the cellulose dissolved. After several minutes the field was black, which indicated that the birefringent material had disappeared. Under the conditions of this experiment, balloon-like swellings which commonly arise when cotton fibers are similarly treated [15], were not observed.

The raw and dewaxed flax fibers were practically identical in their behavior. The residue which remained after treating them with cuprammonium reagent was isotropic and stained deeply with ruthenium red (fig. 2). It consisted of intercellular substance, and of material from the primary wall and lumen, and parts of the secondary wall. When handled and dissected with microneedles this residue appeared gelatinous and rubbery, and was less readily torn apart than similar residues from cotton. Whereas in cotton the pectic substances are usually restricted to the primary wall and to the lumen [15], in flax cells this material, which appears to be of a pectic nature and which stains with ruthenium red, is present in the secondary wall also. It is distributed in narrow lamellas, which are especially prominent around the lumen (fig. $3, A$ ). The existence of these lamellas can be verified by focusing, shading, and gently moving the specimen by applying pressure to the cover glass.

The individual cells of depectinized fibers separated from each other more easily than the cells of raw and dewaxed fibers. In cuprammonium reagent they dissolved almost completely, leaving only a small amount of residue, which exhibited no definite cellular structure.

The examination of cross sections of raw, dewaxed, and depectinized 
fibers confirmed the results obtained with single fibers. By means of the device of Hardy [16], fibers were cut into sections about 10 microns thick. The sections were placed on microscope slides and then examined as cuprammonium hydroxide solution was drawn under the cover glass. The sections swelled, and in a short time the cellulose appeared to be dissolved. The residue from sections of raw and dewaxed flax was relatively large in amount, isotropic, stained with ruthenium red, and consisted in part of insoluble material from the region around the lumen (fig. 3, B). Cross sections of depectinized flax fibers dissolved in the reagent, leaving only a small amount of disorganized residue.

\section{LAMELLAS}

Under high magnification the secondary walls of plant fibers exhibit diverse structural patterns which are sometimes visible in untreated cells, but which usually stand out clearly only after the cells have been swollen. The presence of concentric lamellas in the cell wall of the cotton fiber has been clearly established [15, 17, 18]. That the wall of the flax cell has a similar configuration is suggested by the work of Tammes [2], Nodder [3], Searle [5], Anderson [7], Aldaba [19], and others. Additional evidence in support of such a structure was obtained in the present investigation.

Cuprammonium reagent dissolves the cellulose of the fibers in a relatively short time. In suitable dilutions of the reagent, however, complete dissolution of the cellulose does not occur; instead the fibers swell considerably and thereby reveal many details of structure. When single cells or small groups of flax cells were placed in cuprammonium hydroxide which had been diluted with 3 to 4 volumes of concentrated ammonium hydroxide, they swelled to several times their original diameter. Upon focusing midway between the upper and lower surfaces of such a swollen flax cell, layers or lamellas running parallel to the axis were discernible in the wall (fig. 4, A and B). Lamellas were similarly observed in swollen cross sections of the cells (fig. 5). Individual lamellas varied in thickness from 0.1 to 0.2 micron. ${ }^{4}$ In both cases, upon staining with Congo red, alternating layers of densely and of lightly stained cellulose became prominent. Between crossed nicols these sections showed alternating layers of strongly and of weakly birefringent material.

Although in longitudinal view the lamellas usually ran parallel to the long axis of the cell, this pattern was occasionally altered. At certain points the lamellas did not maintain their cylindrical shape but converged over the lumen to form dome-shaped structures, or "caps." As shown in figure 4, B, two of these domes lay next to each other. Usually, only the innermost lamellas formed these structures, the outermost layers continuing parallel to the axis of the cell and enclosing the "compartments" within. These observations appear to be in agreement with those of Aldaba [19], who studied the development of the cell wall in bast fibers of Boehmeria (ramie) and Linum (flax). Apparently in the earlier stages of cellular differentiation the protoplasm of a single cell behaves more or less as a unit, thereby giving rise to lamellas which extend usually along the entire length of the cell wall. In the later stages of development the compartments

The width of the lamellas was obtained by dividing the thickness of the wall of the unswollen fiber by the number of layers counted after swelling. 


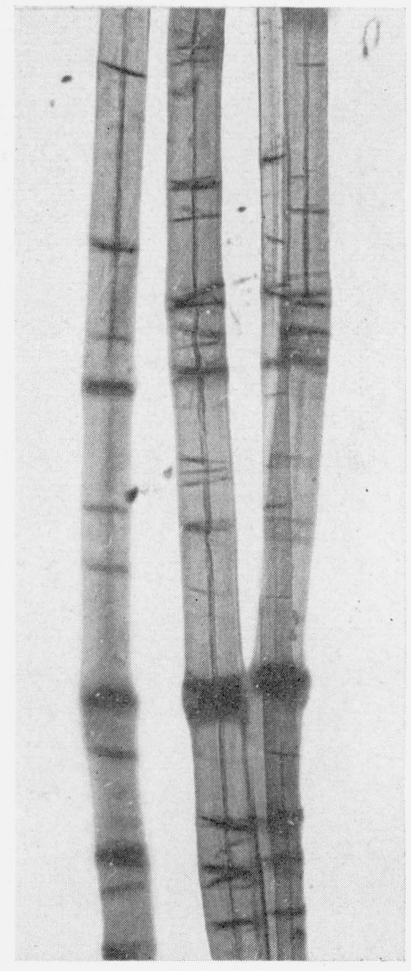

Figure 1.-Transverse markings of flax fibers.

Several flax cells separated from a fiber and treated with zinc chloride-iodine to show the transverse markings. Magnification $\times 100$. 


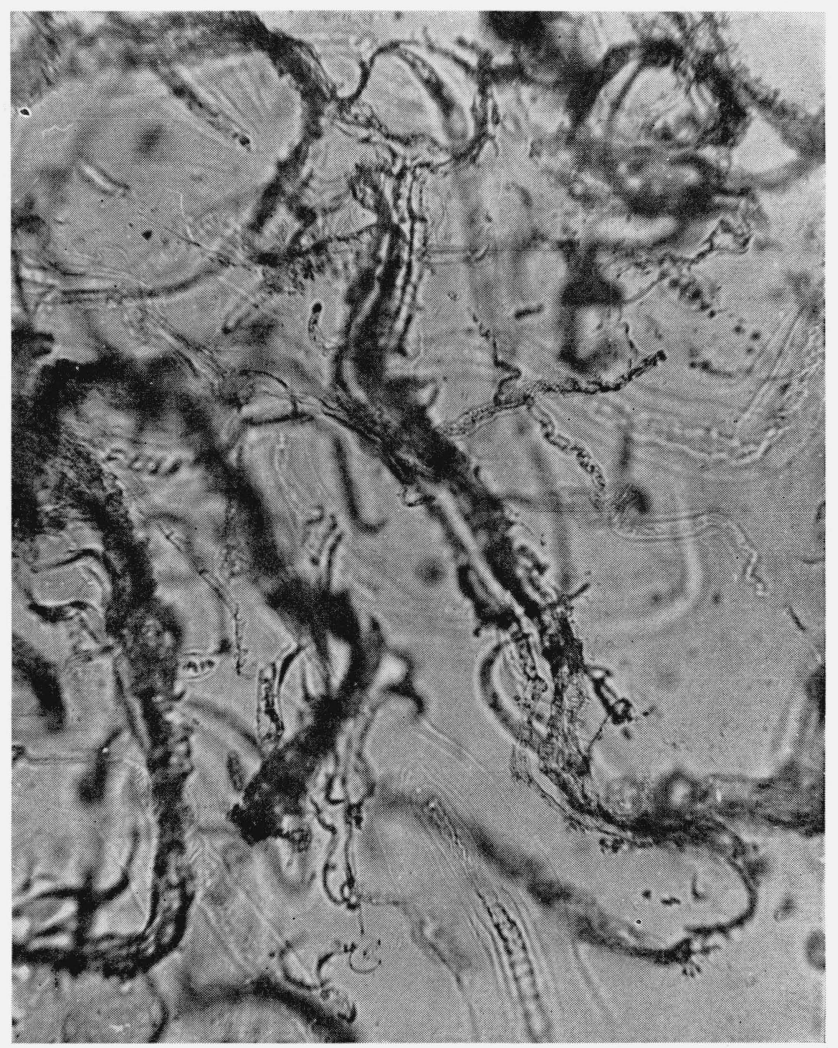

Figure 2.-Dewaxed flax fibers in cuprammonium hydroxide solution.

Residue which remains after the cellulose of the fibers has dissolved in the reagent. Stained with ruthenium red. Magnification $\times 100$. 

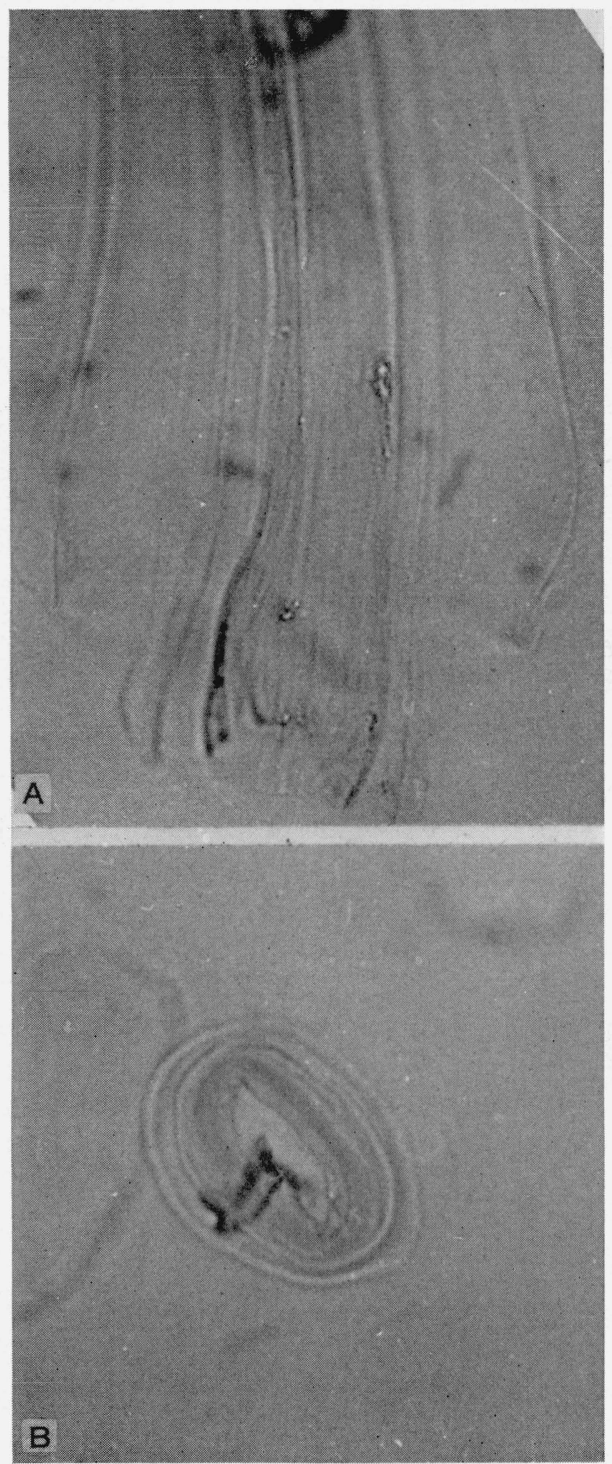

FiGURE 3.-Residue from dewaxed fibers after treatment with cuprammonium reagent.

$A$, Longitudinal view of residue from part of a cell; $B$, cross section of residue from a single cell. Stained with ruthenium red. Magnification $\times 500$. 

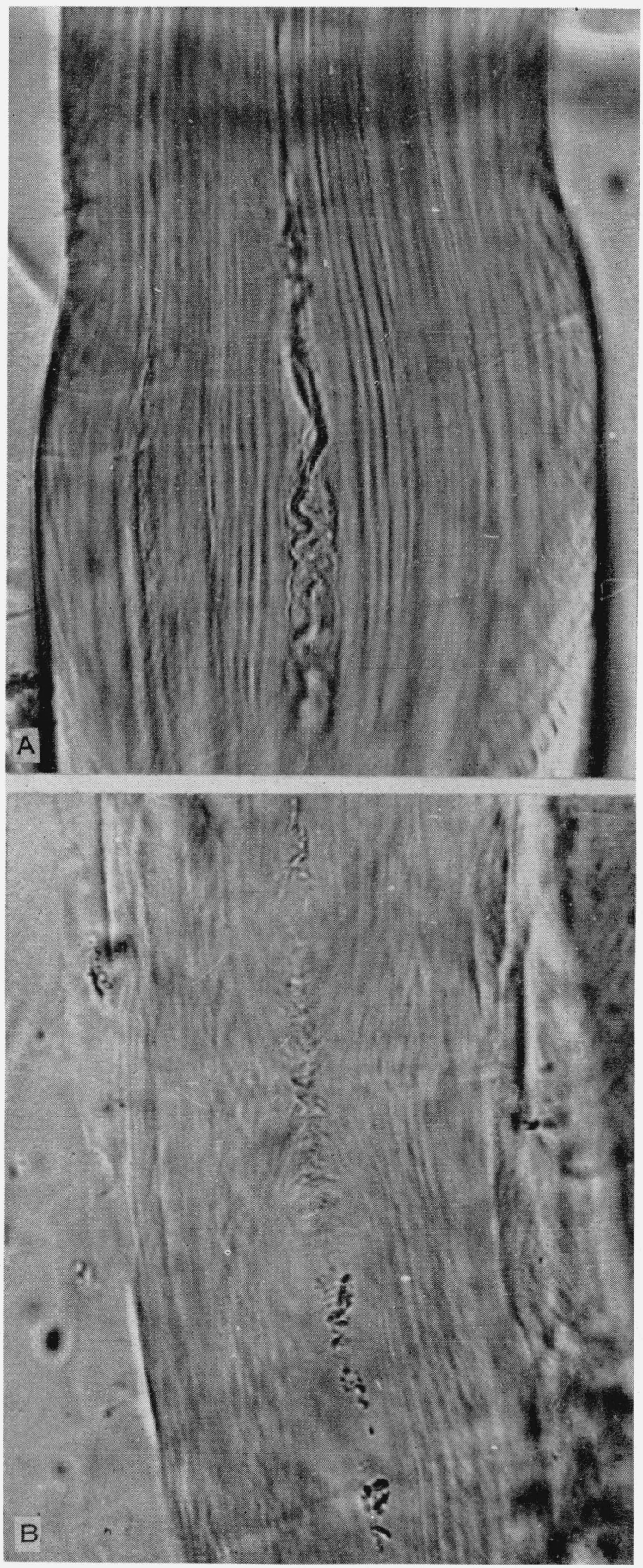

Figure 4.-Lamellas in longitudinal view.

$A$, Single cell, showing lamellas parallel to the long axis; $B$, single cell, showing formation of "compartments" by some of the inner lamellas. Cells swollen in dilute cuprammonium hydroxide and stained with Congo red. Magnification $\times 500$. 


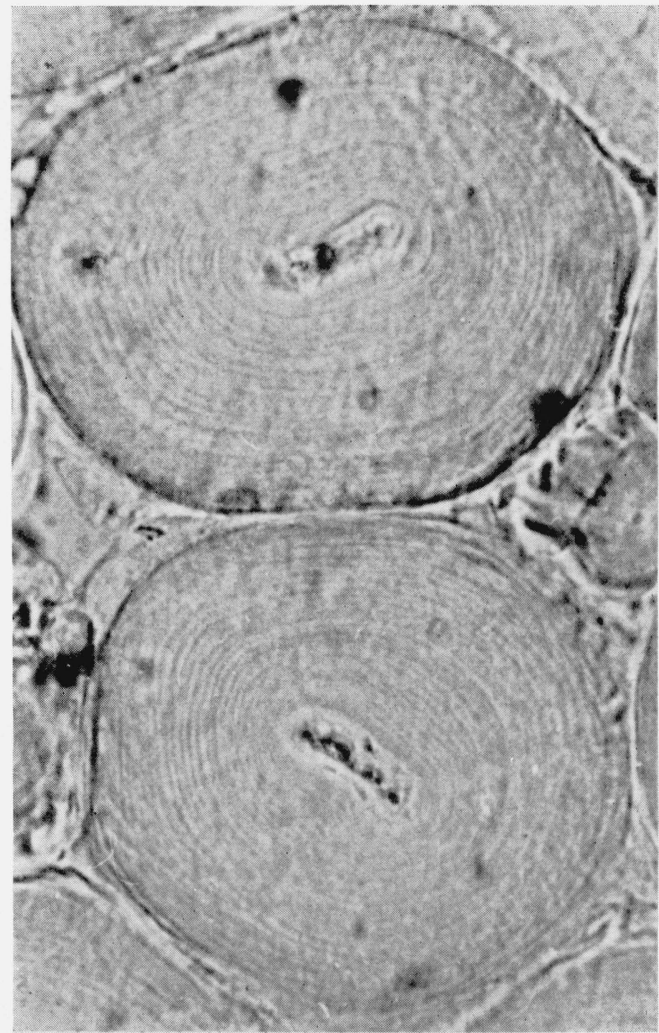

Figure 5.-Lamellas in cross section.

Two adjacent cells after swelling in dilute cuprammonium hydroxide and staining, with Congo red. Magnification $\times 500$. 
are formed in localized regions of the cell, which give rise to additional lamellas enclosed within those previously deposited.

In order to investigate the lamellar structure of flax fibers from different regions of the plant, several flax stems each about $96 \mathrm{~cm}$ in length, were selected and divided into 16 segments in the following: manner. Starting at the base, fifteen $6-\mathrm{cm}$ segments were cut off. The remaining part, which included the branching tip and which sometimes slightly exceeded $6 \mathrm{~cm}$, constituted the 16 th segment. Several series of experiments were then run on the fibers, which were manually separated from each of these regions. First, the fibers were cut into thin cross sections, and the width of the cell walls was measured with a calibrated ocular micrometer. Although considerable variation was found, the measurements indicated that the wall is thicker in the cells at the base of the stem than in those at the tip (table 1). As the cells mature, an initial rapid increase in thickness of the wall appears to be followed by a further more gradual increase. Second, cross sections were swollen in dilute cuprammonium hydroxide, and the lamellas were counted. Finally, the lamellas were counted in longitudinal view in swollen cells from each region. Although there was an appreciable variation in the number of lamellas at any one level of the stem, the number was greater in the cells at the base of the stem than in those at the tip. Figure 6 shows graphically the number of lamellas in relation to the position of the cell in the stem.

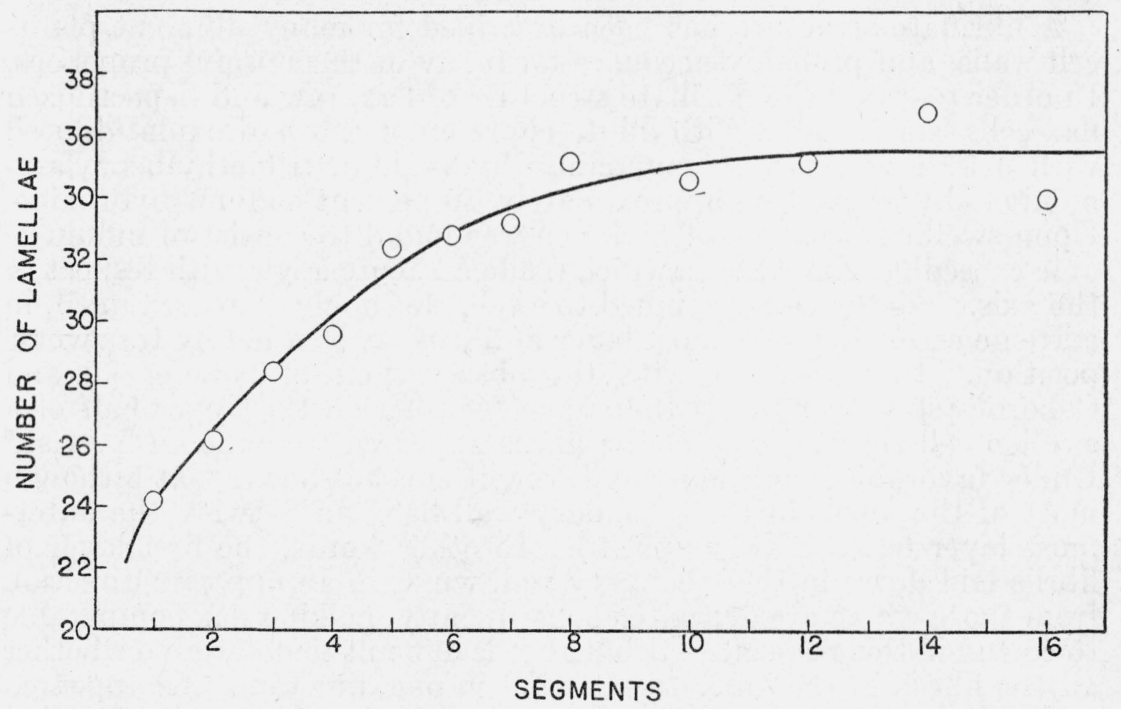

FIgURE 6.-Number of lamellas in cells from various regions of the stem.

The segments represent a distance of $6 \mathrm{~cm}$ each, and are numbered from the tip to the base of the stem. (Each point of the curve represents the average of 20 counts.)

The examination of cross sections (fig. 7) and of cells from living plants confirmed the above observations. The wall often showed a lamellar pattern even in unswollen sections. The lumens of the growing fibers were sharp and irregular in outline, and in some cells the lamellas of the secondary wall appeared wrinkled and folded and 
TABLE 1.-Thickness of the wall of cells from fibers in various regions of the stem [The segments represent a distance of $6 \mathrm{~cm}$ each and are numbered from the tip to the base of the stem.]

\begin{tabular}{|c|c|c|c|c|c|}
\hline Segment & $\begin{array}{l}\text { Thickness } \\
\text { (microns) } \\
\text { arithmetic } \\
\text { mean of } 40 \\
\text { measurements }\end{array}$ & $\begin{array}{l}\text { Standard } \\
\text { deviation } \\
\text { (microns) }\end{array}$ & Segment & $\begin{array}{l}\text { Thickness } \\
\text { (microns) } \\
\text { arithmetic } \\
\text { mean of } 40 \\
\text { measurements }\end{array}$ & $\begin{array}{l}\text { Standard } \\
\text { deviation } \\
\text { (microns) }\end{array}$ \\
\hline $\begin{array}{l}1 \\
2 \\
3 \\
4 \\
5 \\
6\end{array}$ & $\begin{array}{l}5.5 \\
6.5 \\
7.1 \\
7.0 \\
7.4 \\
7.0\end{array}$ & $\begin{array}{l} \pm 1.4 \\
\pm 1.3 \\
\pm 1.4 \\
\pm 1.5 \\
\pm 1.0 \\
\pm 2.2\end{array}$ & $\begin{array}{l}8 \\
10 \\
12 \\
14 \\
16\end{array}$ & $\begin{array}{l}7.5 \\
7.3 \\
8.4 \\
8.2 \\
7.7\end{array}$ & $\begin{array}{l} \pm 1.8 \\
\pm 1.4 \\
\pm 1.6 \\
\pm 1.7 \\
\pm 1.5\end{array}$ \\
\hline
\end{tabular}

only loosely held together. At the tip of the stem, where the cell walls were thin, there were fewer lamellas than in the walls of mature fibers from the base.

Because of the similarity in the lamellar structure of the flax and cotton fibers, it seems probable that the deposition of lamellas in flax may be related to environmental factors, as has been shown for cotton [15, 17, 18]. However, because of the complex structure of the flax stem, the time at which the fibers originate in the stem is unknown and their development cannot be followed.

\section{FIBRILLATE STRUCTURE}

A fibrillate structure has been described for many different plantcell walls, and probably accounts for many of their useful properties. In order to study the fibrillate structure of flax, raw and depectinized flax cells were treated with dilute cuprammonium hydroxide (diluted with 3 to 4 volumes of ammonium hydroxide), trimethylbenzylammonium hydroxide, or approximately 10 percent sodium hydroxide. Upon swelling, the wall of each cell was found to consist of innumerable exceedingly fine fibrils which made an acute angle with respect to the axis. As the cell continued to swell, this angle increased until, in extreme cases, the outermost layer of fibrils lay in a nearly transverse position. In agreement with the observations of Nodder [3] and Osborne [8], it was found that upon focusing on the upper half of a swollen cell the majority of the fibrils appeared to make an $S$ twist. ${ }^{5}$ Under favorable conditions, however, it can be shown that although most of the fibrils in the secondary wall have an $S$ twist, the outermost layer has a Z twist (fig. 8). In other words, the first layer of fibrils laid down in the secondary wall winds in an opposite direction from those which are deposited subsequently, making flax comparable to cotton in this respect. Although it is difficult to determine whether all the fibrils in the inner layers wind in one direction, this appeared to be the case. Anderson [7], however, found a reversal in direction of fibrillate orientation in alternate lamellas. With continued swelling in the reagent, the outermost layer of fibrils frequently lost its even distribution over the surface of the fibres and became clumped in a few places, thereby restricting the uniform lateral expansion of the swelling fiber (fig. 9).

\footnotetext{
5 According to ASTM Standards on Textile Materials [20], a yarn or cord has an S twist if, when held in a vertical position, the spiral conforms in slope to the central portion of the letter $\mathrm{S}$, and a $\mathrm{Z}$ twist if the spiral conforms to the central portion of the letter $Z$. In the present paper, the same terminology will be applied to fibrils.
} 
The fibrillate structure of the secondary wall was examined further with the aid of the needles of a micromanipulator. Flax cells were first swollen in trimethylbenzylammonium hydroxide and then handled with the microneedles. The cells were flattened, stretched, dissected, and otherwise handled so as to reveal their structural details. By this technique the apparent fibrillate structure of the flax fibers was verified. In some cases, small groups of fibrils were pulled away from the cell, whereas at other times practically all the fibrils were separated from each other and spread out in a thin sheet (fig. 10). When examined with the polarizing microscope the fibrils themselves appeared to be birefringent.

\section{RETTING}

In order to study the changes in structure which take place during retting, comparisons were made of commercially retted flax and of samples which were observed continuously during retting in the laboratory.

The commercially retted (tank-retted) flax straw was darker in appearance and more brittle than the untreated stems of the same variety. The bast fibers were often only loosely held to the central woody portion of the retted stem, and could be removed easily for further examination. These fibers stained rather uniformly with ruthenium red and left a large residue of isotropic material upon treatment with cuprammonium hydroxide solution. As observed in cross section, spaces were sometimes evident around the individual bast cells as if the intercellular substance and the primary wall had been attacked, but for the most part the small groups of cells were still held together in their natural arrangement. Cross sections were also made of retted flax straws in order to observe the changes in all the cells of the stem, and not just in the commercially useful bast fibers. Retting was found to take place first in the cambium layer, and later in certain of the cortical cells which surround the fibers. The cells in these regions are thin-walled, with a high proportion of intercellular substance and primary wall, and are easily accessible to retting agents. In the retted samples these layers still gave a positive test with ruthenium red although the individual cell walls were distorted and crushed. The weakening of these regions allows easy separation of the bast fibers from the woody portion of the stem and from the nonfibrous cells of the cortex.

Similar experiments were also carried out on samples retted in the laboratory. The specimens were placed in water at $95^{\circ} \mathrm{F}$ and were observed daily thereafter for 2 weeks. Observations were made on entire flax straws and on their cross sections. The results of these experiments confirmed and extended the observations made on commercially retted samples. The first cells to be attacked by the retting microorganisms were the thin-walled cells of the cortex and cambium layers [21]. Where the process was continued for a longer time, the primary walls of the flax cells were attacked also (fig. 11), but this did not appear to be the essential feature of retting. The observations suggest that, while retting may depend in part on the removal of intercellular substance and of material from the primary walls of the bast cells, the weakening of the cambium and cortical layers is of greater importance [21, 22].

$463607-42-4$ 


\section{COMPARISON OF FLAX WITH OTHER BAST FIBERS}

While less attention has been paid to the other bast fibers-hemp, jute, ramie-it appears that their structures are similar to those of flax. Upon treatment with cuprammonium reagent the cellulose dissolves, leaving a disorganized isotropic residue resembling that from flax. All of these fibers show transverse surface markings, which become more prominent after treatment with zinc chloride-iodine. Whereas in flax, hemp, and sometimes in ramie, these markings often form the letter " $\mathrm{X}$ ", this does not occur in jute. After swelling to many times their original diameter, all the bast fibers show both lamellas and fibrils in their cell walls.

The identification of bast fibers by ordinary microscopic techniques is often difficult and uncertain. The moisture test, in which the direction of movement of one end of the fiber is observed during wetting and drying, has been suggested as a further means of distinguishing them [11]. Accordingly, it was decided to examine all of the available samples of these fibers in order to determine the usefulness of this test. Samples of raw fibers, and others which had been processed in various ways, were used. The test was carried out in the following manner. A small piece of paper was cemented to one end of the fiber perpendicular to its axis. This refinement of technique was helpful, although not essential, in accurately determining the twist. The fiber was then placed in water for $30 \mathrm{sec}$ to $1 \mathrm{~min}$ to ensure thorough wetting, whereupon it was removed and allowed to dry in air. The fiber was held vertically and the direction of twist observed by looking down at the paper indicator. By alternate wetting and drying, the test may be repeated many times on a single fiber. During wetting, the fibers usually show a twist opposite to that observed during drying. With few exceptions, the following generalizations, in agreement with those of Nodder [3] and Reimers [23], appear to hold. The drying twist of flax and ramie is counterclockwise, whereas the twist for hemp and jute is clockwise. The speed of twisting was not uniform for any one type of fiber. For example, some hemp fibers twisted clockwise very rapidly, whereas others moved only slowly in that direction. Generally, however, the motion is more rapid in flax and ramie than in hemp and jute.

The results of the moisture test suggest that the variations in drying behavior may be caused by differences in the fundamental structure of the two groups of fibers. That differences in structure do exist was revealed by noting the direction of orientation of the fibrils in swollen fibers. As described in an earlier section of this paper, a flax cell consists of many fibrils, oriented at an acute angle with respect to the long axis of the fiber. The majority of these fibrils have an $S$ twist, but the outermost layer has a Z twist (fig. 8). The fibrillate structure of cells from ramie fibers was found to be identical. Swelling treatments did not reveal the fibrillate structure in hemp and jute as clearly as in flax and ramie. However, with microneedles, fibrils were dissected from the former. The outermost layer of fibrils showed a $Z$ twist, as in flax and ramie, but unlike them, the majority of the fibrils appeared to be oriented nearly parallel to the axis. Figure 12 shows, diagrammatically, the direction of fibrillate orientation in the bast fibers and is similar to sketches of the micellar orientation in these fibers as reported by Reimers [23]. 


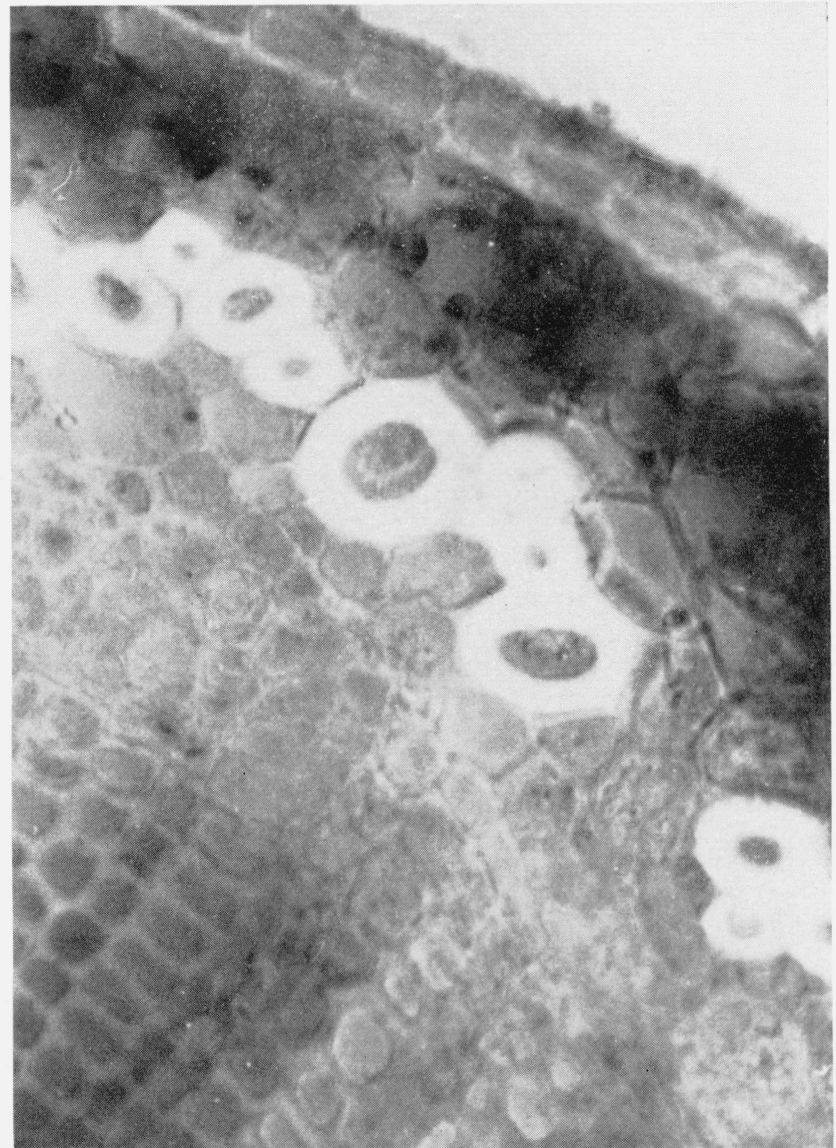

Figure 7.-Cross section of the flax stem.

Part of a cross section of the stem of a growing flax plant, showing the thick-walled fiber cells surrounded by other tissues. Magnification $\times 500$. 


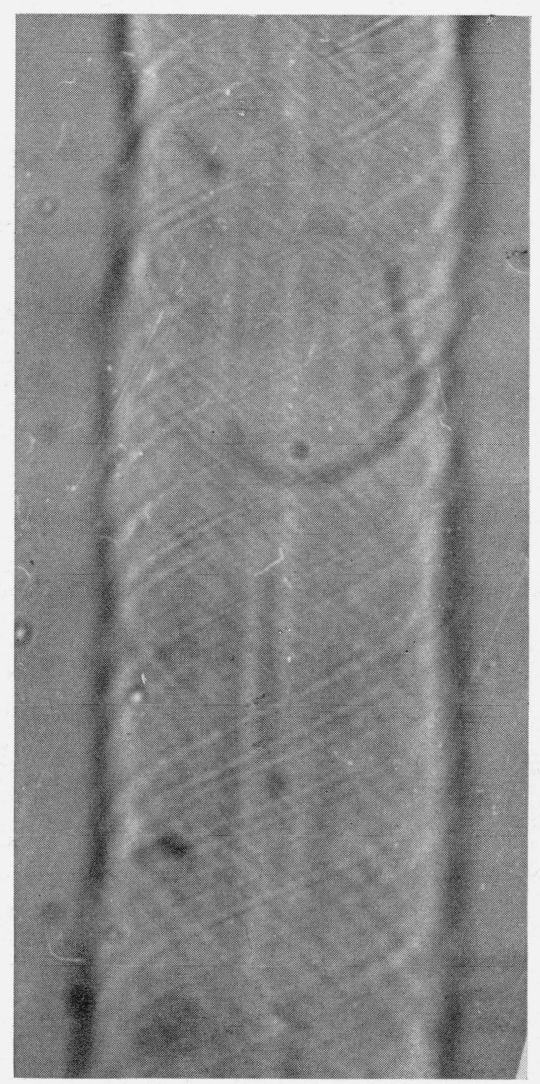

FiguRE 8.-Fibrillate structure of flax.

A single cell swollen in dilute cuprammonium hydroxide, showing the $Z$ twist of the fibrils in the outer layer and $S$ twist of the fibrils in the layers beneath. Magnification $\times 500$. 


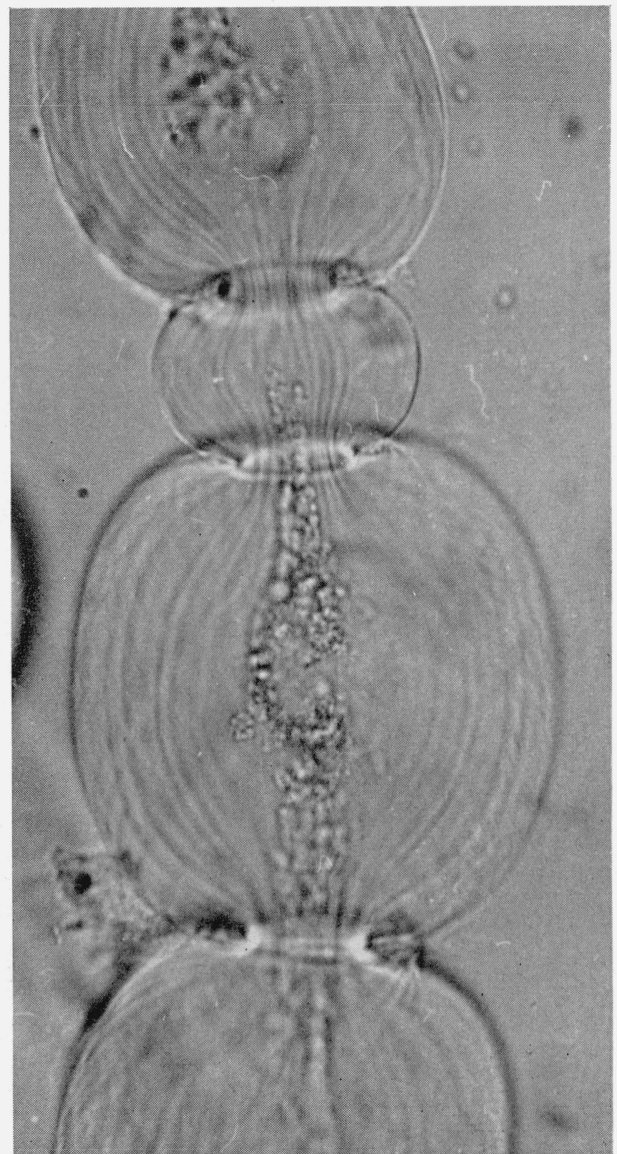

Figure 9.-Irregular swelling of a flax cell.

A depectinized cell in dilute cuprammonium hydroxide, showing irregular swelling because of the constricting influence of the outermost layer of fibrils. Lamellas, as well as some protoplasmic material in the lumen, are also shown. 


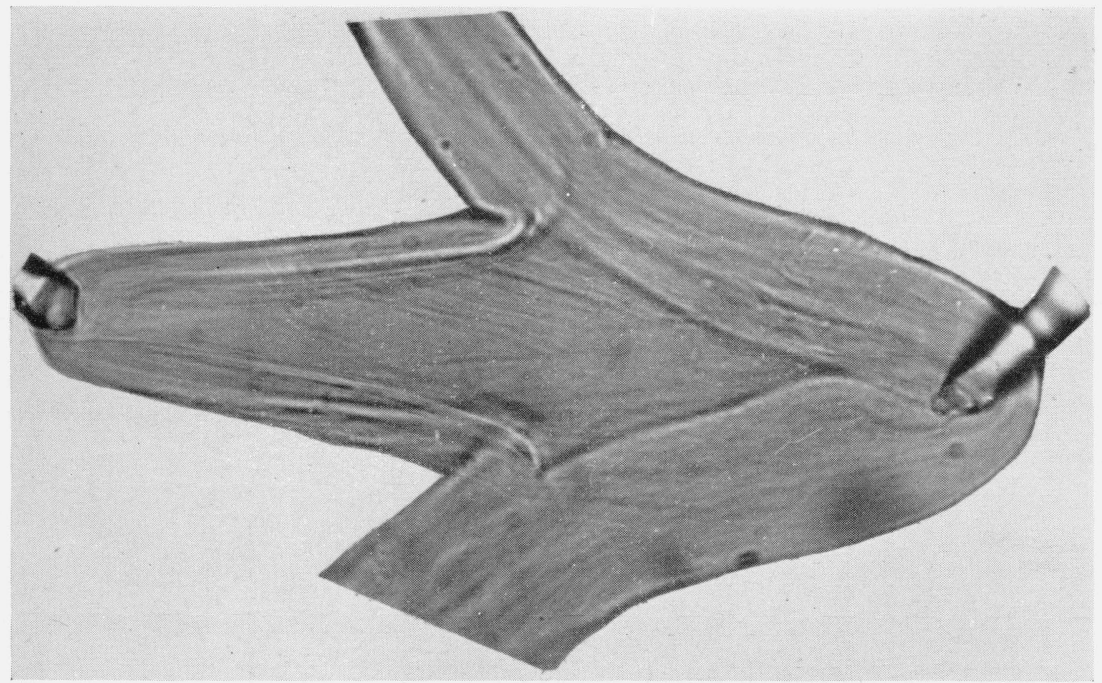

Figure 10.-Microdissection of a single flax cell.

Cell swollen in trimethylbenzyl ammonium hydroxide and dissected with microneedles. Magnification $\times 360$. 


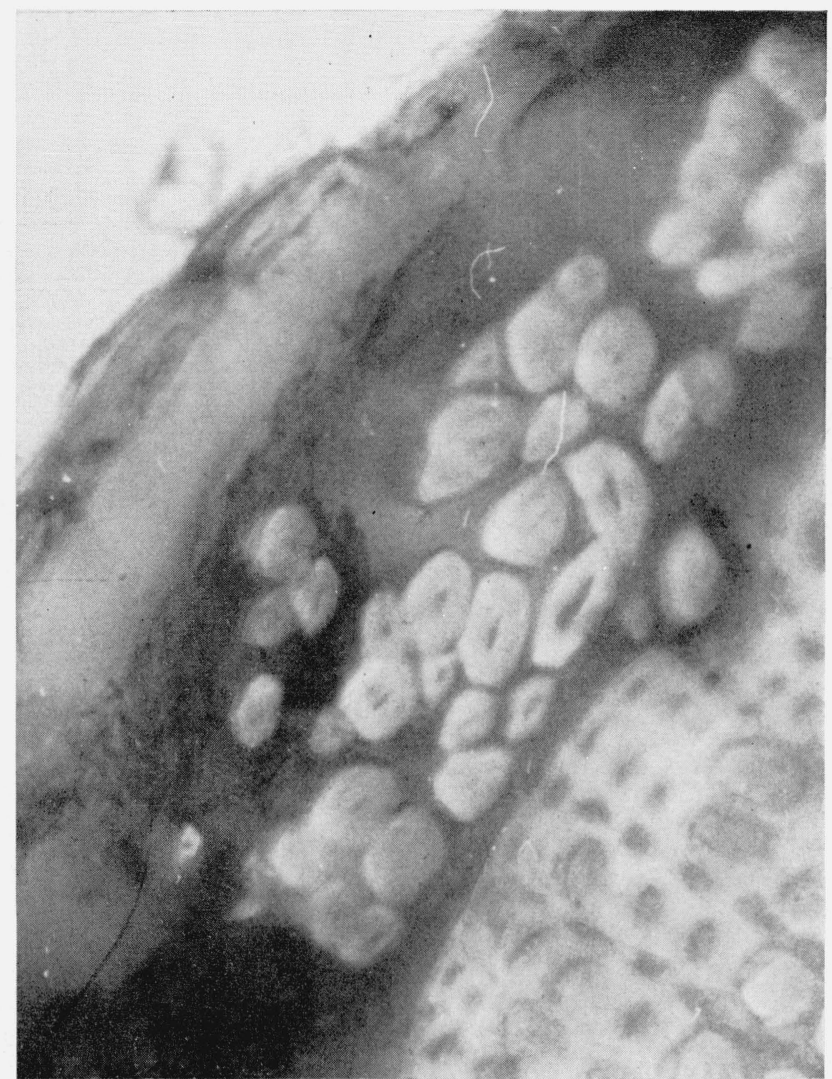

FiguRE 11.-Retted flax straw.

Part of a cross section of a retted flax stem, showing the break-down of the cells surrounding the fibers, and in this case the separation of the fiber cells from each other because of overretting. Compare with figure 7 . Stained with ruthenium red. Magnification $\times 500$. 


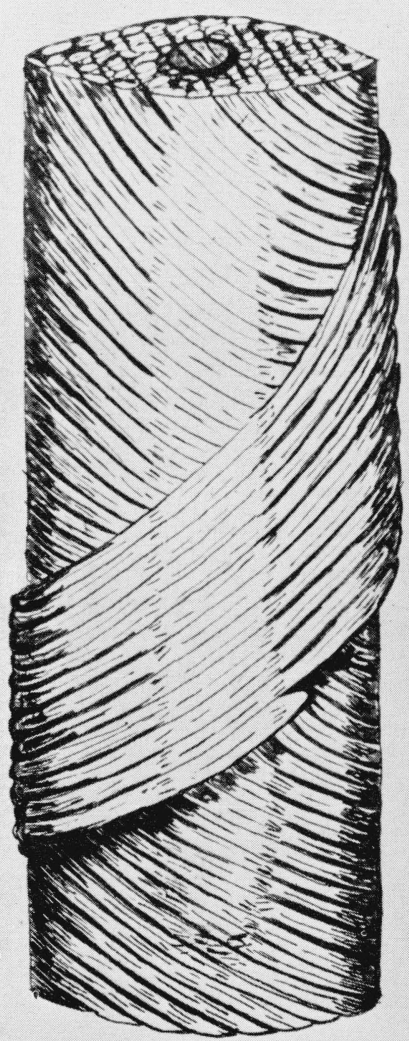

A

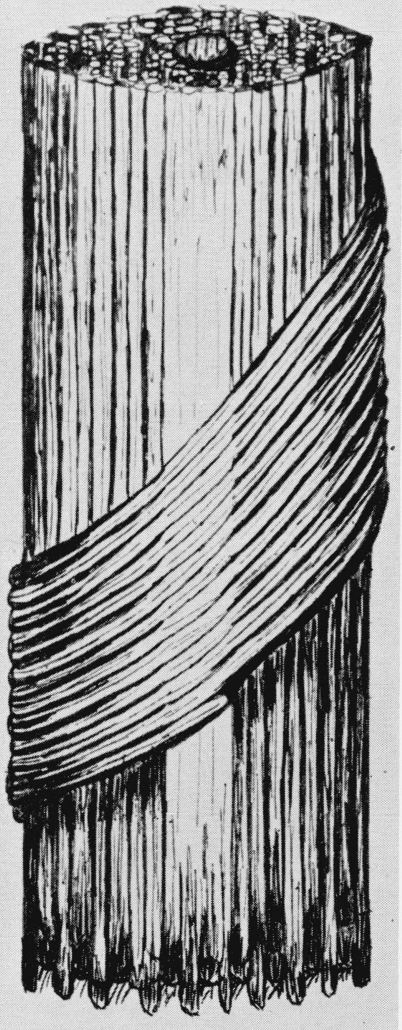

B

FIGURE 12.-Schematic drawing of the arrangement of fibrils in the cells of bast fibers. $A$, Flax and ramie; $B$, hemp and jute. 
In order to see whether there was any similarity between the behavior of yarns with various twists, and fibers with different fibrillate orientations, several yarns with $\mathrm{S}$ and $\mathrm{Z}$ twists were given the moisture test. Yarns with an $S$ twist were found to turn counterclockwise when losing moisture and clockwise when taking it up. The reverse was true for yarns with a $Z$ twist. This suggests the following analogy with bast fibers. In flax and ramie the direction of twist appears to be determined largely by the bulk of fibrils, which make an $S$ twist. When drying, for instance, the tendency of the outermost layer of fibrils with the $Z$ twist to turn the fiber in a clockwise direction is overcome by the very many more fibrils whose orientation favors a counterclockwise movement. In hemp and jute the parallel orientation of the majority of fibrils does not influence the fiber to turn either one way or the other during moisture changes. In these fibers the $Z$ twist of the fibrils in the outer later appears to be the determining factor, thereby causing a clockwise drying twist and a counterclockwise twist during wetting.

While it is recognized that during swelling the angle which the fibrils make with the fiber axis may be changed in magnitude, studies with the polarizing microscope indicate that the general direction of orientation is unaltered. When the fibers were mounted in water and examined between crossed nicols and a selenite plate some of the fibers were opposite in appearance to others. Flax and ramie were indigo at $0^{\circ}$ and orange red at $90^{\circ}$, whereas hemp and jute were orange red at $0^{\circ}$ and indigo at $90^{\circ}$. Upon rotating the fibers the color changes were more pronounced in the first than in the second of the above groups. In both groups color variations occurred in different fibers and even in different regions of the same fiber, but in general when flax and ramie were placed at $0^{\circ}$ the interference colors rose in the color scale, whereas for hemp and jute the interference colors fell. These observations, which are in agreement with those of Herzog [6], indicate an opposite orientation of the cellulose in the two groups of fibers. In cotton, contrasting colors indicative of differences in orientation occur within a single fiber and upon swelling it is seen that in a single fiber the direction of fibrillate orientation is frequently reversed [15]. It is interesting to note, accordingly, that when the moisture test was applied to single cotton fibers they twisted either clockwise or counterclockwise during drying, and sometimes different parts of the same fiber twisted in opposite directions. Occasionally no movement was observed. These experiments indicate that a close correlation exists between the fibrillate orientation of the fibers and some of their physical properties.

\section{REFERENCES}

[1] I. W. Bailey, Ind. Eng. Chem. 30, 40 (1938).

[2] T. Tammes, Natuurkundige Verhandelingen van de Hollandshe Maatschappij der Wetenschappen te Haarlem. De Erven Loosjes, Haarlem (1908).

[3] C. R. Nodder, J. Textile Inst. 13, T161 and 213 (1922).

[4] C. R. Nodder, Trans. Faraday Soc. 20, 251 (1924).

[5] G. O. Searle, J. Textile Inst. 15, T371 (1924).

[6] A. Herzog, Die Unterscheidung der Flachs- und Hanffaser. Julius Springer, Berlin (1926).

[7] D. B. Anderson, Am. J. Bot. 14, 187 (1926).

[8] G. G. Osborne, Textile Research 5, 351 and 431 (1935). 
[9] M. H. Branfoot (M. H. Carrè), Dept. of Scientific and Industrial Research Food Investigation, Special Report No. 33 for 1928. His Majesty's Stationery Office, London (1929).

[10] R. T. Mease, J. Research NBS 22, 271 (1939) RP1179.

[11] T. M. Plitt, Circular of the National Bureau of Standards C423 (1939).

[12] L. Mangin, Compt. rend. 116, 653 (1893).

[13] D. B. Anderson and T. Kerr, Ind. Eng. Chem. 30, 48 (1938).

[14] C. W. Hock and M. Harris, J. Research NBS 24, 743 (1940) RP1309; Am. Dyestuff Rptr. 29, No. 12, 287-292 (1940).

[15] C. W. Hock, R. C. Ramsay and M. Harris, J. Research NBS 26, 93 (1941) RP1362; Am. Dyestuff Rptr. 30, 53 (1941).

[16] J. I. Hardy, U. S. Dept. of Agriculture Circular 378 (1935).

[17] W. L. Balls, Proc. Roy. Soc. (London) [B] 90, 342 (1919).

[18] T. Kerr, Protoplasma 27, 229 (1937).

[19] V. C. Aldaba, Am. J. Bot. 14, 17 (1927).

[20] A. S. T. M. Standards on Textile Materials, Am. Soc. for Testing Materials, Philadelphia (1941).

[21] R. L. Davis, U. S. Dept. of Agric. Bul. No. 1185 (1923).

[22] J. V. Eyre and C. R. Nodder, J. Textile Inst. 15, T237 (1924).

[23] H. Reimers, Textilberichte $2,367,381$, and 420 (1931).

Washington, April 3, 1942. 